\title{
MODIFICAÇÕES NA CONDIÇÃO FÍSICA DAS SEMENTES DE CENOURA EM EQUIPAMENTO DE RECOBRIMENTO ${ }^{1}$
}

\author{
EVERTONMAKSUD MEDEIROS ${ }^{2}$, LEOPOLDOBAUDET $^{3}$, WOLMERBROD PERES $^{3}$, EBERSONDIEDRICHEICHOL ${ }^{4}$
}

\begin{abstract}
RESUMO - O objetivo do trabalho foi avaliar equipamento desenvolvido para o recobrimento de sementes e seu efeito na qualidade física de sementes de cenoura em função da aderência de diversos materiais inertes em diferentes proporções: aglomerante (vermiculita) nas proporções 2:1 e 3:1; adesivo (acetato de polivinil) e o polímero + corante "Color coat” $($, bem como a adição do fungicida Thiram + Carbendazin $(250 \mathrm{ml}$ para cada $100 \mathrm{~kg}$ de semente). Foram obtidas informações quanto à modificação do tamanho, forma, peso e teor de água das sementes da cultivar Tropical. Mediante a utilização de peneiras detectou-se que as sementes mantiveram-se individualizadas, com modificação de tamanho, peso e forma. Os resultados obtidos permitiram concluir que o equipamento de recobrimento de sementes mostra-se funcional na aderência das diferentes camadas e o polímero associado ao corante fornece aparência satisfatória às sementes de cenoura recobertas; o equipamento de recobrimento de sementes é eficiente na modificação do tamanho, forma e do peso das sementes de cenoura; o acetato de polivinil é eficiente adesivo no recobrimento de sementes de cenoura e as sementes de cenoura absorvem água após o recobrimento, devendo sofrer secagem artificial antes do armazenamento.
\end{abstract}

Termos para indexação: Daucus carota, máquina de revestimento, tamanho, forma, peso.

\section{MODIFICATIONS IN PHYSICAL CONDITION OF CARROT SEEDS WITH COATING EQUIPMENT}

\begin{abstract}
The objective of this work was to evaluate physical quality of carrot seed run through an equipment developed for coating in function of adherence of several inert materials in different concentrations: agglomerate Vermiculite in proportions of 2:1 and 3:1; sticker Polyvinyl Acetate; and colorant "Color coat ${ }^{\circledR}$ ", as well as addition of fungicide Thiram + Carbendazin ( $250 \mathrm{ml}$ for each $100 \mathrm{~kg}$ of seed). Information was taken about carrot cultivar Tropical seed size, shape, weight and moisture. Using screens, it was detected that seeds remain isolated and modified size, weight and original form. The results obtained allow to conclude that the equipment for seed coating was functional in relation to the adherence of several layers, as well as the polymer + colorant produce satisfactory appearance to the seeds; the equipment was efficient in modifying size, shape and weight of carrot seeds; the Polyvinyl acetate was an efficient sticker for carrot seed coating and seed coating increased carrot seed moisture so seeds must be artificially dried for storage.
\end{abstract}

Index terms: Daucus carota, coating equipment, size, form, weight.

\footnotetext{
${ }^{1}$ Submetido em 18/12/2003. Aceito para publicação em 15/07/2004. Parte da dissertação de mestrado do primeiro autor apresentada a UFPel/FAEM.

${ }^{2}$ Eng $^{\circ} \mathrm{Agr}^{\circ}$, Professor Substituto, UFPel/FAEM. E-mail: maksud@terra.com.br
}

\footnotetext{
Professor, Programa de Pós-Graduação em Ciência e Tecnologia de Sementes, UFPel/FAEM; e-mail: lmbaudet@ufpel.edu.br

${ }^{4}$ Eng $^{\circ} \mathrm{Agr}^{\circ}$, mestrando do Programa de Pós-Graduação em Ciência e Tecnologia de Sementes, UFPel/FAEM.
} 


\section{INTRODUÇÃO}

A semente não mais representa somente um meio de propagação de uma nova cultura, mas carrega também uma nova forma de gerenciamento da tecnologia agrícola. A agregação de valor às sementes, utilizando métodos e tecnologias de produção como a de recobrimento de sementes, é a principal exigência de um mercado cada vez mais competitivo. Para isto são necessárias sementes com alta uniformidade de germinação/emergência e que produzam plântulas com alto potencial de crescimento (Baudet \& Peres, 2004).

Segundo Schimidt (1982), a primeira meta buscada através do recobrimento de sementes é uma modificação no tamanho e na forma das sementes, tornando-as mais facilmente visíveis. As sementes revestidas resultam do recobrimento por um filme formando uma camada sólida ou líquida, mediante a aplicação de sólidos dissolvidos ou suspensivos, de tal forma a permitir a formação de uma capa, mais ou menos contínua, capaz de revestir sua cobertura protetora natural. Assim tratadas, as sementes mantém-se individualizadas, modificando o peso e a forma original. Para fixação dessas camadas são utilizados adesivos que, numa classificação genérica, estão divididos em três grupos: orgânicos, minerais e sintéticos.

Dentre os adesivos sintéticos existentes no mercado, novos produtos como polivinil pirrolidona, poliuretanos e resinas (Sampaio \& Sampaio, 1994) vêm sendo utilizados e, segundo Howelson et al. (1987), o polivinil pirrolidona é um adesivo muito apropriado para recobrir sementes que precisam suportar qualquer tipo de impacto ou abrasão. Este é um material de elevado custo, utilizado onde os incrementos de custo são compensados pelos benefícios que aportam.

Juntamente com os corantes, formando uma fina película externa, são utilizados polímeros. Segundo West (1983), um polímero ideal não deve ser permeável ao vapor d'água, mas deve ser obrigatoriamente solúvel em água e permitir a embebição das sementes.

Ao avaliar a precisão na colocação da semente revestida no solo, como um método para o estabelecimento de plântulas de cenoura, cebola, alface e beterraba açucareira, Tonkin (1979) concluiu que o uso de sementes recobertas possibilita a obtenção de populações adequadas, com altas taxas de emergência e com a mínima utilização de mão- de- obra.

As sementes recobertas apresentam elevados peso e custo. Por outro lado, torna-se contraditório o efeito físico da cápsula sobre a semente, pois além de ser de alguma forma um obstáculo, necessita maior quantidade de água para dissolver a cobertura (Doni Filho, 1980).

Trabalhando com sementes de cenoura revestidas e não, em solo com e sem irrigação, Tomic (1976) observou que nas condições irrigadas, os tratamentos equivalem-se. No entanto, sob condições de solo seco, as sementes nuas apresentaram melhor desempenho.

Comparando os custos de produção de cenoura, utilizando sementes nuas e revestidas, Yamanouchi (1988) verificou maior preço da semente revestida. Porém, ao levar em conta o custo do desbaste, constatou redução de $13 \%$ no custo unitário. Ao utilizar diversas sementes revestidas de espécies olerícolas, Kagohara (1987) concluiu que o recobrimento de sementes reduz significativamente os custos de mão-de-obra, permitindo programar a semeadura e distribuir uniformemente as sementes no solo.

Para Hathcock \& Dernoeden (1984), a vantagem da prática do recobrimento de sementes é o fornecimento de condições de sobrevivência a cada uma das sementes, melhorando o meioambiente específico onde ocorrerá a germinação e o desenvolvimento das plântulas.

As vantagens do recobrimento de sementes, citadas por Duran (1989) são: a precisão na semeadura e no espaçamento de sementes pequenas e de formato irregular; a redução nos custos de produção; a diminuição de impactos que sofrem as sementes durante a semeadura; a formação de um microambiente mais uniforme ao redor das sementes no solo; a possibilidade de inclusão de produtos úteis às sementes; a economia de sementes; a redução de mão de obra de ressemeadura e desbaste; a melhoria das características de fluxo e plantabilidade, e aperfeiçoamento das condições de segurança, minimizando a exposição dos operadores ao produto químico, especialmente quando são utilizados produtos sistêmicos.

Outras vantagens do recobrimento de sementes são também apontadas por Edie (1997), a redução da exposição dos operadores aos pesticidas, a facilidade no manejo do tratamento quanto às quantidades de produto e a adição de peso as sementes melhorando o contato semente-solo.

Equipamento específico para o recobrimento de sementes foi desenvolvido por Peres (2001) que permite a individualização das sementes pela modificação do peso e da forma original com camadas de adesivos (goma arábica e acetato de polivinílica) e de aglomerante (vermiculita).

O objetivo do trabalho foi avaliar o equipamento destinado ao recobrimento de sementes, utilizando sementes de cenoura em função da aderência de diversos materiais inertes 
(aglomerante, adesivo e corante), bem como a adição do fungicida, para obter maiores informações quanto à modificação da forma, peso e umidade das sementes.

\section{MATERIAL E MÉTODOS}

O equipamento desenvolvido por Peres (2001), foi instalado na Unidade de Beneficiamento de Sementes da Universidade Federal de Pelotas, constituído por dez componentes: (1) estrutura, (2) moegas, (3) aplicador do adesivo, (4) aplicador do aglomerante, (5) tambor rotativo, (6) secador, (7) captação de pó, (8) aplicador do corante, (9) misturador-transportador e (10) acionamento (Figura 1).

As moegas e os depósitos foram abastecidos manualmente em fluxo contínuo. Foi colocada uma tela de nylon sobre as peneiras, para que todos os componentes do recobrimento (sementes recobertas, sementes não recobertas e vermiculita não aderida às sementes) deslizassem sobre essa tela para avaliar o rendimento do equipamento. O tempo de permanência da semente no circuito foi de 10 minutos, na rotação do tambor de $10 \mathrm{rpm}$ e na temperatura da massa de sementes de $43^{\circ} \mathrm{C}$.
As sementes de cenoura (Daucus carota L.) da cultivar Tropical de tamanho médio, produzidas na safra 2001/2002, num lote de $25 \mathrm{~kg}$, foram homogeneizadas, separadas em cinco sub-lotes de $5 \mathrm{~kg}$ cada um e acondicionadas em sacos de tecido de algodão. As sementes estavam tratadas com fungicida Prodine $(200 \mathrm{~g})+$ Thiram $(600 \mathrm{~g})$ na concentração de $0,25 \%$ ( $250 \mathrm{ml}$ de fungicida para cada $100 \mathrm{~kg}$ de semente). Utilizouse Thiram $(600 \mathrm{~g})+$ Carbendazin $(200 \mathrm{~g})$, na concentração de $0,25 \%$, para as sementes recobertas que foram tratadas com fungicida sobre as camadas de recobrimento. $\mathrm{O}$ aglomerante utilizado foi vermiculita nas doses de $10 \mathrm{~kg}(2: 1)$ e $15 \mathrm{~kg}(3: 1)$ $/ 5 \mathrm{~kg}$ de sementes. Como material adesivo dos aglomerantes nas sementes, foi utilizada a cola branca - acetato de polivinil $(0,421 \mathrm{em} 5 \mathrm{~kg}$ de sementes) na diluição em água destilada de $10 \%$. Para melhor identificação das sementes após o recobrimento, utilizou-se o corante "Color coat $\AA$ " da empresa Rigran de Porto Alegre, Rio Grande do Sul, cor verde $(0,421$ / $5 \mathrm{~kg}$ de sementes), na diluição em água destilada de $20 \%$.

Com o equipamento em funcionamento, para cada sublote foram determinadas as quantidades utilizadas de adesivo, aglomerante e corante. $\mathrm{O}$ rendimento do equipamento foi

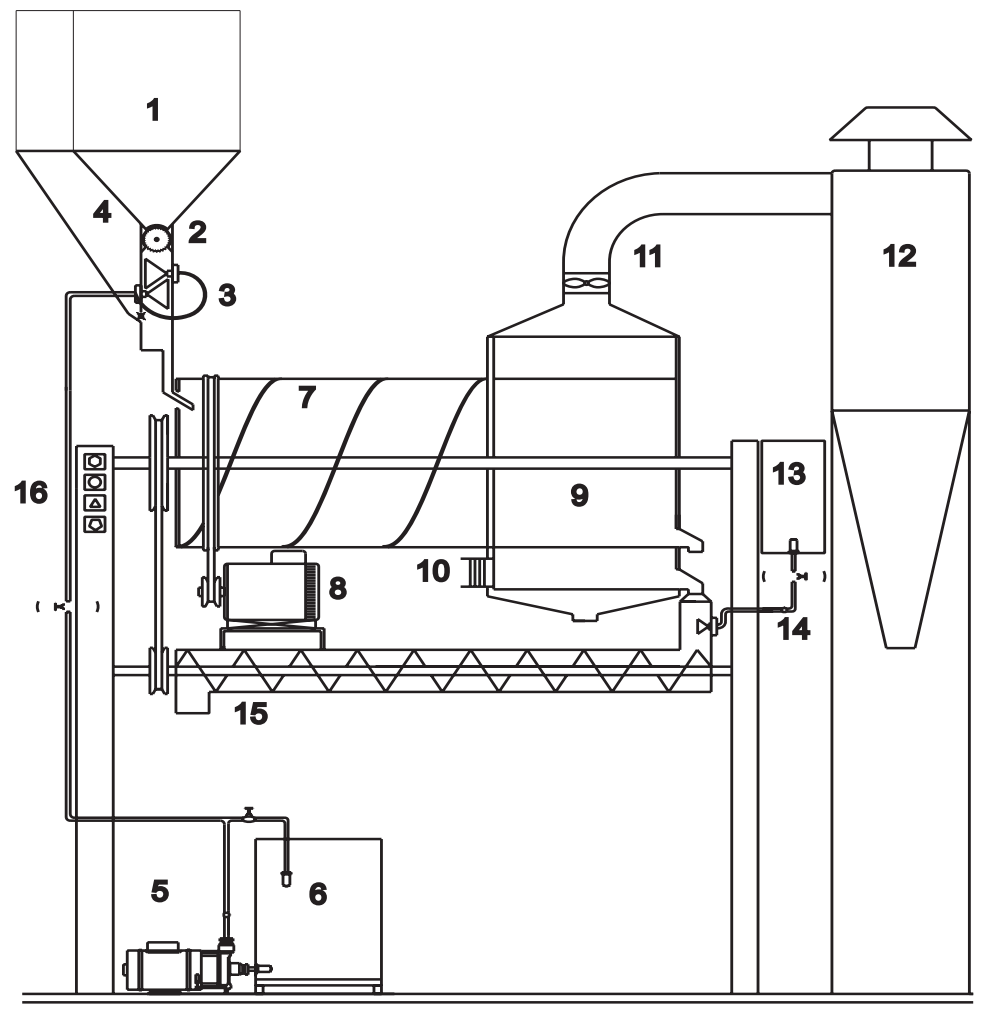

Legenda

1- Moega

2- Dosador

3- Aspersor

4- Reservatório de Aglomerante

5- Moto-Bomba

6- Reservatório do Adesivo

7- Cilindro Rotativo

8- Acionamento Elétrico

9- Peneiras Cilíndricas

10- Resistência Elétrica

11- Exaustor

12- Ciclone

13- Reservatório do Corante

14- Aspersor

15- Rosca Misturadora

16- Quadro de Comando

FIGURA 1. Diagrama do equipamento para recobrimento de sementes (Peres, 2001). 
obtido pela razão entre a soma dos pesos de sementes, adesivo, aglomerante e corante inicialmente colocados e o peso das sementes revestidas. O resíduo ocorrido no processo foi considerado redução de rendimento do equipamento.

Determinação do teor de água das sementes: realizada em estufa a $105 \pm 3{ }^{\circ} \mathrm{C}$, durante 24 horas, conforme as Regras para Análise de Sementes (Brasil, 1992). Peso de 1.000 sementes: determinado sobre oito repetições contendo cada uma 100 sementes, pesadas em balança analítica marca Gehaka ${ }^{\circledR}$ modelo 2000, com duas casas decimais, e os resultados expressos em gramas, conforme Brasil (1992). Tamanho das sementes revestidas: após o recobrimento, as sementes foram passadas em um conjunto de peneiras planas metálicas sobrepostas para determinar as dimensões das sementes revestidas. Análise estatística: foi utilizado o delineamento inteiramente casualizado com quatro repetições

\section{RESULTADOS E DISCUSSÃO}

A Tabela 1 mostra o desempenho do equipamento no recobrimento de semente de cenoura, quanto à adição de aglomerante, adesivo, corante e fungicida. Pode-se verificar que as quantidades utilizadas de semente, adesivo, aglomerante e corante não interferiram no rendimento médio final da máquina, ao se processar o recobrimento.

A cada $100 \mathrm{~kg}$ de semente, o equipamento possibilitou o recobrimento de 82,5 e $88,7 \mathrm{~kg}$ de semente na proporção de $2: 1$ e de 77,3 e $83,2 \mathrm{~kg}$ de semente na proporção $3: 1$, sem e com fungicida. Esses dados permitem determinar as proporções dos produtos a serem utilizados para a obtenção do tratamento.

A Tabela 2 apresenta o desempenho do equipamento por meio do peso de mil sementes de cenoura, cujo aumento foi da ordem de duas vezes e meia a mais para o tratamento de 2:1 e de aproximadamente quatro vezes para o tratamento $3: 1$, em relação às sementes não recobertas.

$\mathrm{O}$ processo de recobrimento permitiu alterar a largura e a espessura das sementes, modificando portanto o formato das sementes. As dimensões das sementes sem o recobrimento variaram entre $2,2 \times 19 \mathrm{~mm}$ na peneira interna e $2,0 \times 19 \mathrm{~mm}$ na peneira externa. As sementes recobertas na proporção de aglomerante de 2:1, sem e com fungicida, variaram entre 2,8 $\mathrm{x} 19 \mathrm{~mm}$ e 2,2 x 19mm, enquanto que as sementes recobertas na proporção de aglomerante de 3:1, sem e com fungicida, variaram entre $2,8 \times 19 \mathrm{~mm}$ e 3,2 x 19mm nas peneiras interna e externa, respectivamente, o que resultou na recomendação de peneiras, conforme indicado na Tabela 3.

Esta modificação do formato vem favorecer a semeadura de precisão. As sementes recobertas tiveram tamanho e forma modificados, passando, segundo a classificação dos fabricantes de equipamentos de semeadura, de sementes miúdas (de difícil semeadura) para sementes graúdas (de fácil mecanização). As novas dimensões obtidas possibilitariam que as sementes recobertas fossem utilizadas na maioria das semeadoras mecânicas.

Como as sementes de cenoura apresentam desuniformidade de tamanho, sugere-se que além da padronização feita pelas empresas de sementes, seja realizada antes do recobrimento, uma nova classificação para melhor uniformizar o lote quanto ao tamanho de sementes.

$\mathrm{O}$ equipamento possui um sistema de secagem no final da operação de recobrimento. O teor de água das sementes de cenoura após o recobrimento foi determinado para testar o desempenho do secador acoplado. Os resultados (Figura 2)

TABELA 1 - Avaliação do equipamento de recobrimento de sementes de cenoura, na confecção da camada de recobrimento pelo peso de mil sementes. Pelotas, RS, 2002.

\begin{tabular}{ccccccccc}
\hline Tratamento & $\begin{array}{c}\text { Aglomerante } \\
(\mathrm{kg})\end{array}$ & $\begin{array}{c}\text { Semente } \\
(\mathrm{kg})\end{array}$ & $\begin{array}{c}\text { Adesivo } \\
(1)\end{array}$ & $\begin{array}{c}\text { Polímero } \\
\text { corante }(1)\end{array}$ & $\begin{array}{c}\text { Peso } \\
(\mathrm{kg})\end{array}$ & $\begin{array}{c}\text { Resíduo } \\
(\mathrm{kg})\end{array}$ & $\begin{array}{c}\text { Peso } \\
\text { final }(\mathrm{kg})\end{array}$ & $\begin{array}{c}\text { Rendimento } \\
\text { final }(\%)\end{array}$ \\
\hline $\begin{array}{c}\text { A 2:1 sem } \\
\text { fungicida }\end{array}$ & 10,0 & 5,0 & 0,42 & 0,42 & 13,05 & 2,13 & 15,18 & 82,5 \\
\hline $\begin{array}{c}\text { A 2:1 com } \\
\text { fungicida }\end{array}$ & 10,0 & 5,0 & 0,42 & 0,42 & 14,03 & 2,04 & 16,07 & 88,7 \\
\hline $\begin{array}{c}\text { A 3:1 sem } \\
\text { fungicida }\end{array}$ & 15,0 & 5,0 & 0,42 & 0,42 & 16,10 & 2,96 & 19,06 & 77,3 \\
\hline $\begin{array}{c}\text { A 3:1 com } \\
\text { fungicida }\end{array}$ & 15,0 & 5,0 & 0,42 & 0,42 & 17,34 & 2,01 & 19,35 & 83,2 \\
\hline
\end{tabular}

$\mathrm{A}=$ aglomerante nas proporções $10 \mathrm{~kg}(2: 1)$ e $15 \mathrm{~kg}(3: 1)$ por $5 \mathrm{~kg}$ de semente 
TABELA 2. Avaliação do equipamento de recobrimento de sementes de cenoura, na confeç̧ão da camada de recobrimento pelo peso de mil sementes. Pelotas, RS, 2002.

\begin{tabular}{cc}
\hline Tratamento & Peso de mil sementes $(\mathrm{g})$ \\
\hline Sem recobrimento & 1,6 \\
A 2 : 1 Sem Fungicida & 4,0 \\
A 2 : 1 Com Fungicida & 4,1 \\
A 3 : 1 Sem Fungicida & 6,1 \\
A 3 : 1 Com Fungicida & 6,6 \\
\hline
\end{tabular}

$\mathrm{A}=$ aglomerante nas proporções $10 \mathrm{~kg}(2: 1)$ e $15 \mathrm{~kg}(3: 1)$ por $5 \mathrm{~kg}$ de semente.

TABELA 3. Peneiras recomendadas para a classificação de sementes recobertas de cenoura. Pelotas, RS, 2002.

\begin{tabular}{lll}
\hline Tratamentos & $\begin{array}{l}\text { Peneira Interna } \\
(\mathrm{mm})\end{array}$ & $\begin{array}{l}\text { Peneira Externa } \\
(\mathrm{mm})\end{array}$ \\
\hline Sem recobrimento & $2,2 \times 19$ & $2,0 \times 19$ \\
A 2 : 1 Sem Fungicida & $2,8 \times 19$ & $2,2 \times 19$ \\
A 2 : 1 Com Fungicida & $2,8 \times 19$ & $2,2 \times 19$ \\
A 3 : 1 Sem Fungicida & $3,2 \times 19$ & $2,8 \times 19$ \\
A 3 : 1 Com Fungicida & $3,2 \times 19$ & $2,8 \times 19$ \\
\hline
\end{tabular}

$\mathrm{A}=$ aglomerante nas proporções $10 \mathrm{~kg}(2: 1)$ e $15 \mathrm{~kg}(3: 1)$ por $5 \mathrm{~kg}$ de semente. mostraram que não houve secagem eficiente, visto que as sementes recobertas apresentaram teor de água superior a $23 \%$, sendo que as não recobertas, que não passaram pelo equipamento, estavam com teor de água de 7,8\%. Logo após o recobrimento, foi necessário realizar secagem estacionária para preparar as sementes para o armazenamento. Nota-se que as sementes recobertas apresentam maior teor de água, exigindo maior intensidade do processo de secagem após a operação de recobrimento.

Os resultados alcançados possibilitam verificar que as sementes após o recobrimento apresentaram modificação quanto à forma, ao tamanho e ao peso, facilitando assim a semeadura, concordando com as afirmações de Schimidt (1989), Duran (1989) e Edie (1997), embora necessite maior quantidade de água para a hidratação da cobertura, conforme Doni Filho (1980).

\section{CONCLUSÕES}

O equipamento de recobrimento de sementes mostra-se funcional na aderência das diferentes camadas e o polímero associado ao corante fornece aparência satisfatória às sementes recobertas de cenoura.

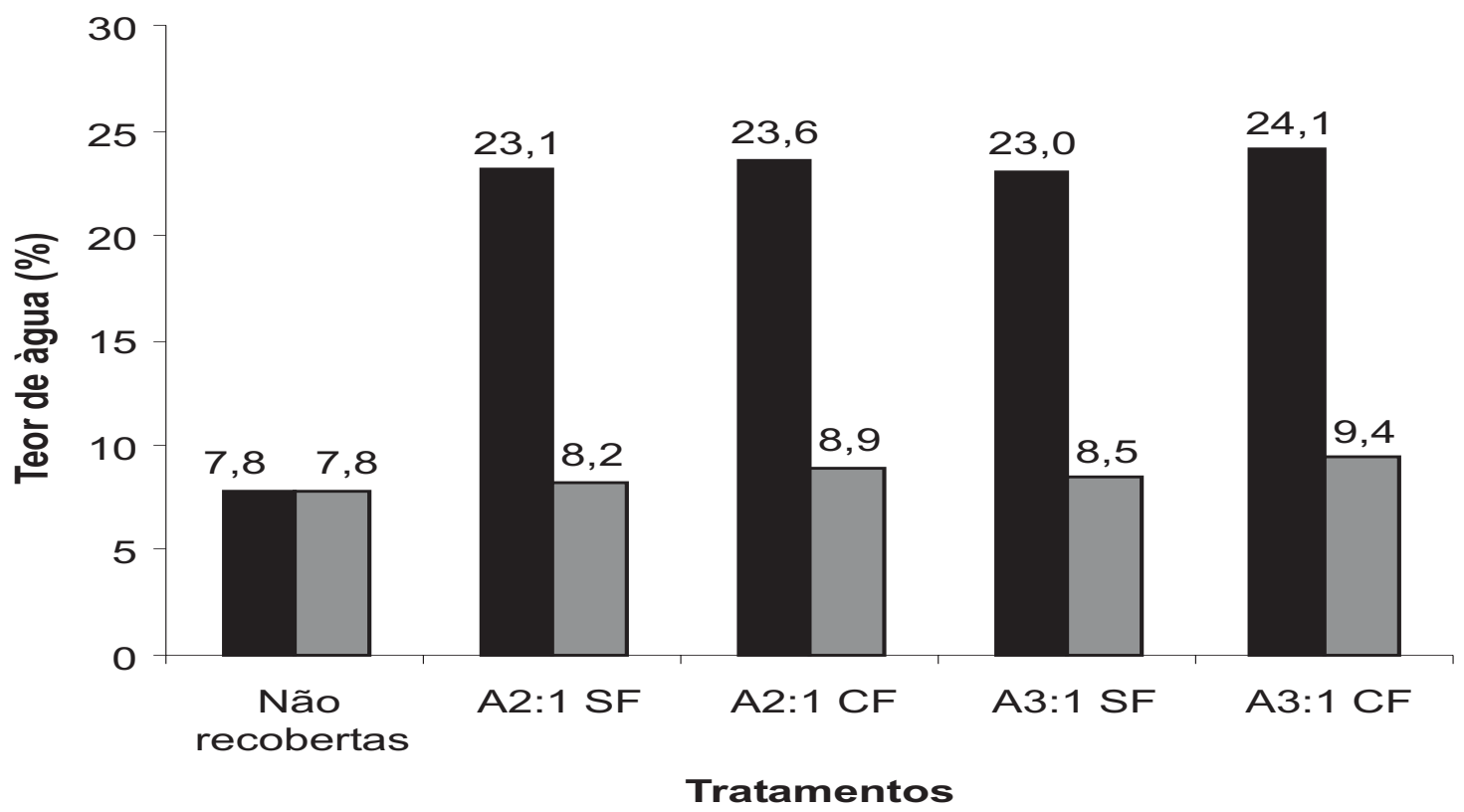

Após o recobrimento

Após a secagem

FIGURA 2. Teor de água (\%) das sementes de cenoura após o recobrimento e após a secagem artificial. Pelotas, RS, 2002. 
O equipamento de recobrimento de sementes é eficiente na modificação do tamanho, da forma e do peso das sementes de cenoura.

O acetato de polivinil é um eficiente adesivo no recobrimento de sementes de cenoura.

As sementes de cenoura absorvem água no processo de recobrimento, devendo ser submetidas a secagem artificial antes do armazenamento.

\section{REFERÊNCIAS}

BAUDET, L. ; PERES, W. Recobrimento de sementes. Seed news, Pelotas, v.8, n.1, p.20-23. 2004.

BRASIL. Ministério da Agricultura e Reforma Agrária. Regras para análise de sementes. Brasília: SNDA/DNDV/CLAV, 1992. $365 p$.

DONI FILHO, L. Semeadura de precisão: a falta de uma solução definitiva. Seminários de olericultura. Viçosa: UFV, 1980. v. 2. p.412-435.

DURAN, J.M. Pre-acondicionamiento y recubrimiento de semillas hortícolas. Agricultura, Madrid. n.679, p.128-131, 1989.

EDIE, B. Equipment: the full treatment. Germination, Winnipeg, v.1, n.5, p.12-15. 1997.
HATHCOCK, A.L. ; DERNOEDEN, P.H Seed germination of tall fescue a kentuchy bluegrass as affected by adhesives. Journal of Horticultural Science, London v.19, n.3, p.442-443. 1984.

HOWESON, J.G; EWING, M.A; THORN, C.W. Inoculation and line of medie seed. Western Australian, 1987. 65p.

KAGOHARA, L. A linha de montagem chega à horta. Revista guia rural, Osasco, n.3, p.64-66, 1987.

PERES, W.B. Desenvolvimento e avaliação de equipamento destinado ao recobrimento de sementes. 2001. 128f. Tese (Doutorado em Ciêcia e Tecnologia de Sementes).Universidade Federal de Pelotas, Pelotas, 2001.

SAMPAIO, T.G. ; SAMPAIO, N.V. Recobrimento de Sementes. Informativo ABRATES, Brasília, v.4, n.3, p.20-52, 1994.

SCHIMIDT, P. Pelleted seed in ornamental plant growing, three to ten seeds per pellet: direct sowing in ready to market units. Horticultural Abstracts, New York, v.52, p.534, 1982.

TOMIC, F. The effect of irrigation and seed pelleting on carrot vields. Horticultural Abstracts, London, v. 47, n.4, ref. 3731, 1976.

TONKIN, J.H.B. Pelleting and other presowing treatments. Advances in Seed Technology, v.4, p.84-105, 1979.

WEST, S.H. Polymers as moisture to maitain seed quality. Crop Science, Madison, v.25, p.91-94, 1983.

YAMANOUCHI, M. Peletização de sementes: cenoura Nantes peletizada. In: SEMINÁRIO DE HORTALIÇAS, 1, 1988, São Paulo. Anais... São Paulo: 1988. p.23-27. 